\title{
Menin represses JunD transcriptional activity in protein kinase C $\theta$-mediated Nur77 expression
}

\author{
Hyungsoo $\mathrm{Kim}^{1 *}$, Ji-Eun Lee ${ }^{1 *}$, \\ Bu-Yeon $\mathrm{Kim}^{1,2}$, Eun-Jung Cho ${ }^{3}$ \\ Seong-Tae $\mathrm{Kim}^{4}$ and Hong-Duk Youn ${ }^{1,2,5}$ \\ ${ }^{1}$ Department of Biochemistry and Molecular Biology \\ Cancer Research Institute \\ ${ }^{2}$ Interdisciplinary Program in Genetic Engineering \\ Seoul National University College of Medicine \\ 28 Yongon-dong, Chongro-gu \\ Seoul 110-799, Korea \\ ${ }^{3}$ College of Pharmacy \\ ${ }^{4}$ College of Medicine \\ Sungkyunkwan University \\ 300 Chunchun-dong, Suwon 440-746, Korea \\ ${ }^{5}$ Corresponding Author: Tel, 82-2-3668-7452; \\ Fax, 82-2-744-4534; E-mail, hdyoun@snu.ac.kr \\ ${ }^{*}$ These authors contributed equally to this work.
}

Accepted 9 September 2005

Abbreviations: bis-IM, bisindoylmaleimide; HDAC, histone deacetylase; MEF2, myocyte enhancing factor 2; MITR, MEF2-interacting transcription repressor; PKC, protein kinase C; RT, reverse transcription; TCR, T cell receptor

\footnotetext{
Abstract

TCR signaling leading to thymocyte apoptosis is mediated through the expression of the Nur77 family of orphan nuclear receptors. It has been shown that the Nur77 promoter is activated by at least two signaling pathways, one mediated by calcium and the other by protein kinase C (PKC). MEF2D has been known to regulate Nur77 expression in a calciumdependent manner. The mechanism by which calcium regulates MEF2D is through dissociation of calcium-sensitive MEF2 corepressors (Cabin1/ HDACs, HDAC4/5) and the association with calcineurin-activated transcription factor NF-AT and the coactivator p300. However, little is known about how PKC activates the Nur77 promoter. Herein, we report that PKC $\theta$ targets AP-1 like response element in the Nur77 promoter where JunD constitutively binds. PKC $\theta$ triggers mitogen-activated protein kinaseinediated phosphorylation of JunD, and increases transcriptional activity of JunD, cooperatively with p300. Menin is identified as the transcriptional
}

corepressor for JunD via recruitment of $\mathrm{mSin} 3$ istone deacetylases. In fact, Menin represses $\mathrm{PKC} \theta /$ p300-mediated transcriptional activity of JunD in T cell. Its dynamic regulation of histone modifiers with JunD is responsible for PKC $\theta$-synergistic effect on Nur77 expression in T cell.

Keywords: histone deacetylase; protein kinase C; transcription factors; transcription factor AP-1

\section{Introduction}

T cell receptor (TCR)-mediated apoptosis of immature thymocytes is important for eliminating selfreactive $\mathrm{T}$ cells. The Nur77 family of transcription factors has been identified as crucial mediators for TCR-mediated thymocyte apoptosis (Sebzda et al., 1999; Winoto and Littman, 2002). Nur77 (NGFI-B/ TR3) is an NR4A1-3 subgroup of orphan nuclear receptors (Nur77, NOR- 1, Nurr1) and mediates apoptotic pathways in prostate cancer cells, lung cancer cells, gastric cancer cells as well as immature T cells (Liu et al., 1994; Woronicz et al., 1994; Weih et al., 1996, Uemura and Chang et al., 1998; Li et al., 2000; Lu et al., 2002).

Recent years have witnessed significant advances in our understanding of the calcium-dependent intracellular signaling pathway from TCR to Nur77 transcription. Myocyte enhancing factor 2 (MEF2) has been identified as a key calcium-dependent transcription factor that regulates gene expression in muscle, neuronal, and immune cells (McKinsey et al., 2002). MEF2D, a predominant isoform in T cells, is found to bind to two calcium-dependent DNA elements in the Nur77 promoter and to mediate calcium-dependent induction of Nur77 (Woronicz et al., 1995). We have previously shown that two distinct calcium-mediated pathways are involved in the activation of MEF2 transcription: (i) Calcium, calmodulin-dependent dissociation of a family of MEF2 transcription repressors. Three distinct types of repressors for MEF2 have been identified, Cabin1/Cain (Lai et al., 1998; Sun et al., 1998; Youn et al., 1999; Youn and Liu, 2000), HDAC4, 5, 7, 9 (Miska et al., 1999; Wang et al., 1999; Dressel et al., 2001), and MITR (Sparrow et al., 1999). Among these corepressors, Cabin1 is capable of recruiting Class I HDACs via binding to the corepressor mSin3 while MITR can directly recruit Class I HDACs. It 
was recently reported that $\mathrm{HDAC7}$ serves as a thymus-specific class II histone deacetylase, and regulates Nur77 transcription and TCR-mediated apoptosis (Dequiedt et al., 2003). In the absence of an appropriate TCR signal, MEF2 is bound to most, if not all, of these functionally redundant repressors, silencing the Nur77 promoter. Upon TCR activation and the accompanying increase in intracellular calcium concentration, activated calmodulin binds to all repressors in a manner that is competitive against MEF2, releasing the repressors from MEF2 and allowing the binding of p300 (Youn and Liu, 2000; Youn et al., 2000b). Moreover, calmodulin-dependent kinase (CaMK) I and IV also appear capable of dissociating HDAC4 and 5 from MEF2, in part by causing nuclear export of HDAC4/5 (McKinsey et al., 2000). (ii) Binding of calcineurin-activated NF-AT to MEF2D. NF-AT, a well-known calcineurin substrate in non-activated $T$ cells, translocates from the cytosol into the nucleus where it forms a ternary complex with MEF2 and p300, leading to full activation of Nur77 expression (Blaeser et al., 2000; Youn et al., 2000a).

In addition to calcium signal, TCR also activates protein kinase $C(P K C)$, which acts synergistically with calcium signal to activate the Nur77 promoter and thymocyte apoptosis. PKC family of serine/ threonine kinases is thought to play roles in a variety of tissues and cell types (Altman et al., 2000; Seo et al., 2004). Among these, PKC $\theta$ is expressed predominantly in skeletal muscle and lymphoid organs (Osada et al., 1992; Baier et al., 1993). PKC $\theta$ has been known to regulate the transcription of interleukin-2 in T lymphocytes primarily through the activation of NF-kB (Sun et al., 2000). The transcription factor mediating the activation of Nur77 by $\mathrm{PKC} \theta$, however, remains unknown. Menin is a tumor suppressor protein encoded by MEN1 (multiple endocrine neoplasia type I), a causative gene associated with tumors of parathyroid, enteropancreatic neuroendocrine tissue and anterior pituitary (Chandrasekharappa et al., 1997). Menin has been shown specifically interacts with JunD but not with other members of Jun family (c-Jun, JunB), as their interactions are mediated through the far $\mathrm{N}$-terminal region of JunD that is missing in C-Jun and JunB (Aggarwal et al., 1999). In addition to JunD, Menin is also known to interact with other transcription factors, including $\mathrm{NF}-\kappa \mathrm{B}, \mathrm{Smad} 3$, and Pem, implicating a general role of Menin in regulating transcription (Heppner et al., 2001; Kaji et al., 2001; Lemmens et al., 2001). Menin is known to repress JunD-activated transcription. The detailed molecular mechanism by which Menin represses JunD, however, is still unclear. Gobl et al., recently showed that HDAC inhibitor, trichostatinA reverses Menin-mediated JunD trans- criptional repression, suggesting that HDACs may be involved in Menin-mediated transcriptional repression of JunD and other transcription factors (Gobl et al., 1999). We recently found that Menin represses JunD transcriptional activity by recruiting an mSin3Ahistone deacetylase complex (Kim et al., 2003).

In this study, we identify the primary PKC $\theta$-responsive element in the Nur77 promoter as that of AP-1 and show that JunD is the predominant isoform of AP1 that is bound to the site on the Nur77 promoter. We demonstrated that PKC $\theta$ activates JunD transcriptional activity through MAP kinase-mediated phosphorylation of JunD. We previously showed that Menin represses JunD transcriptional activity through recruitment of $\mathrm{mSin} 3$-histone deacetylase complexes (Kim et al., 2003). The Menin-mediated JunD transcriptional repression is relieved by $\mathrm{PKC} \theta / \mathrm{p} 300-$ mediated transactivation of JunD. Taken together with our previous results that calcium regulates MEF2 transcriptional activity by controlling association of MEF2 with Cabin1-HDAC complexes and p300 acetyltransferase during $\mathrm{T}$ cell apoptosis (Youn et al., 1999; 2000a; Youn and Liu, 2000), these results suggest another regulatory mechanism by which PKC $\theta$ synergizes with calcium to activate Nur77 expression by controlling the association of JunD with HDAC and HAT-containing complexes.

\section{Materials and Methods}

\section{Cell culture and transfections}

Jurkat T cells and D011.10 T hybridoma cells were maintained in RPMI 1640 media containing $1 \mathrm{mM}$ glutamine, $10 \%$ fetal bovine serum, and $50 \mathrm{U} / \mathrm{ml}$ of streptomycin and penicillin. 293 human embryonic kidney (HEK293) cells were grown in DMEM media containing $10 \%$ fetal bovine serum and $50 \mathrm{U} / \mathrm{ml}$ of streptomycin and penicillin. T cells were transfected by electrophoration $(250 \mathrm{~V}, 950 \mu \mathrm{F})$. HEK293 cells were transfected with lipofectamine reagent per manufacturer's protocol (Invitrogen).

\section{DNA constructions}

The constructs for Nur77-promoter driven reporter genes used in this study were prepared by inserting the PCR fragments of Nur77 promoter into PGL2basic vector or pGL2-SV40 promoter vector (Promega). PKC $\theta$ constructs [pEFPKC $\theta$ (A148/E) and pEFPKC $\theta(K 409 / R)]$ were kindly provided by Dr. A. Altman (La Jolla Institute for Allergey and Immunology, San Diego), Menin construct by Dr. C. X. Zhang (CNRS-UMR, France) and Dr. S. K. Agarwal (NIH, Bethesda), pGEX-junD (1-347) by Dr. A. Gobl (Uppsala University Hospital, Sweden). Deletion mu- 
tants of Menin were made by subcloning of PCR fragments into pcDNA3-myc/His vector (Invitrogen). For making mammalian expression vector for $\mathrm{HA}$ tagged human JunD, PCR fragment of JunD (1-347) was inserted into pSG5-HA vector. HA-tagged PICOT expression vector was prepared by inserting cDNA of human PICOT obtained from Marathon-ready human lymph node library (Clontech) into pSG5-HA vector.

\section{Gel shift assay and biotin-streptoavidin affinity pull-down assay}

The nuclear extracts from PMA/ionomycin treated D011.10 cells were prepared by method as described previously (Sun et al., 1998). The nuclear extracts were incubated with c-jun, JunD antibodies (Santa Cruz) for $30 \mathrm{~min}$, and incubated with ${ }^{32} \mathrm{P}$ labelled Nur77 promoter probe for further $30 \mathrm{~min}$, and run at $200 \mathrm{~V}$ on $4 \%$ polyacrylamide gel (sense primer, 5'-GCTCCCTGCGTCAATGGAACC-3'; antisense primer, 5'-GGTTCCATTGACGCAGGGAGC3 ). To confirm the binding of JunD to Nur77 promoter, biotin-labelled Nur77 oligonucleotides (0.1 $\mu \mathrm{M})$ were incubated with D011.10 cell nuclear extracts and streptavidin agarose (Oncogene) in a buffer [25 mM HEPES ( $\mathrm{pH} 7.4), 5 \%$ glycerol, 150 $\mathrm{mM} \mathrm{NaCl}, 0.5 \mathrm{mM}$ EDTA, $1 \mathrm{mM}$ DTT and $1 \mathrm{mM}$ PMSF] for $2 \mathrm{~h}$, washed three times with washing buffer [20 mM HEPES (pH 7.4), $150 \mathrm{mM} \mathrm{NaCl}, 0.5$ mM EDTA, $20 \%$ glycerol, $0.1 \%$ NP-40], subjected to $12 \%$ SDS-PAGE and transferred onto NC membrane, and probed with anti-JunD antibody.

\section{Coimmunoprecipitation}

Transiently transfected DO11.10 T cells or HEK293 cells were harvested after $24 \mathrm{~h}$ and lysed with a lysis buffer [20 mM Tris- $\mathrm{HCl}(\mathrm{pH} 7.4), 150 \mathrm{mM} \mathrm{NaCl}$, $0.5 \%$ NP-40, $1 \mathrm{mM}$ PMSF]. Cell lysates were immunoprecipitated with suitable antibodies along with protein-A/G beads (Santa Cruz). Immunoprecipitates were separated by SDS-PAGE, transferred to nitrocellulose membrane, and immunoblotted with appropriate antibodies. Antibodies for anti-Menin, antiNur77, anti-mSin3A were purchased from Santa Cruz Biotechnology, anti-c-myc and anti-HA monoclonal antibodies from Covance and anti-flag (M2) monoclonal antibody from Sigma.

\section{RNA extraction and reverse transcription (RT)-PCR analysis}

Total RNAs were extracted from murine DO.11.10 cells with TRIzol reagent (Life Technologies, Inc.). cDNAs were synthesized using reverse transcriptase cDNA synthesis kit (Takara, Japan) with total
RNAs as template. The PCR primers used in this study were as follows: Nur77, 5'-GTTGATGTTCCCGCCTTTGCC-3' and 5'-TCAGAAAGACAATGTGTCCAT-3'; $\beta$-actin, 5'-TGACCCAGATCATGTTTGAGACC and 5'-CCATACCCAAGAAGGAAGGC-3'.

\section{Phosphorylation of JunD}

PKC $\theta$ (A148/E)-transfected cell lysates were immunoprecipitated with either anti-PKC $\theta$ (Transduction laboratories), anti-JNK, or anti-ERK antibodies (Santa Cruz). Immunoprecipitates were incubated with $1 \mu \mathrm{g}$ of purified recombinant GST-JunD in kinase reaction buffer for $30 \mathrm{~min}$, then reactants were subjected to $10 \%$ SDS-PAGE. Phosphorylation of GST-JunD was detected by anti-phospho-junD (Ser100) antibody (Upstate).

\section{Results}

\section{PKC is involved in Nur77 induction in $\mathrm{T}$ cells}

To examine the role of PKC in Nur77 induction during $T$ cell apoptosis, we first investigated the effect of PMA, along with ionomycin or both, on Nur77 expression at the mRNA level. When PMA $(40 \mu \mathrm{M})$ was treated for $1 \mathrm{~h}, \mathrm{mRNA}$ of Nur77 was induced albeit lower to the treatment of both PMA and ionomycin (Figure 1A). To determine the effect of PMA on the expression of Nur77 at the protein level, we treated DO.11.10 cells with PMA, ionomycin or both for $3 \mathrm{~h}$. Interestingly, PMA could not trigger the expression of Nur77 protein, whereas ionomycin could result in the expression of Nur77 protein. In fact, we observed that PMA transiently induced mRNA of Nur77 within $1 \mathrm{~h}$, thereafter, mRNA of Nur77 disappeared significantly (data not shown), indicating that PMA alone cannot prolong the expression of Nur77. Nonetheless, PMA synergistically affected the induction of Nur77 protein along with inomycin (Figure 1B), implying that PMA, at least, partially contributes to the induction of Nur77. The optimal induction of Nur77 is achieved with a combination of PMA and ionomycin (Figure $1 A, B)$, indicating that PMA signal is likely to be involved in the activation of the Nur77 promoter. To confirm the participation of PKC, we pretreated D011.10 cells with bisindolylmaleimide-I (bis-IM) for 30 min followed by the activation of D011.10 cells with PMA and ionomycin for another $3 \mathrm{~h}$. Bis-IM inhibited Nur77 induction in a dose-dependent manner (Figure 1C). The significant, albeit incomplete, inhibition of Nur77 by bis-IM supports that PKC is involved in Nur77 induction. It has been known that PKC $\theta$ is a predominant PKC isoform for $\mathrm{T}$ cell development and/or activation (Altman et al., 2000). To 
A

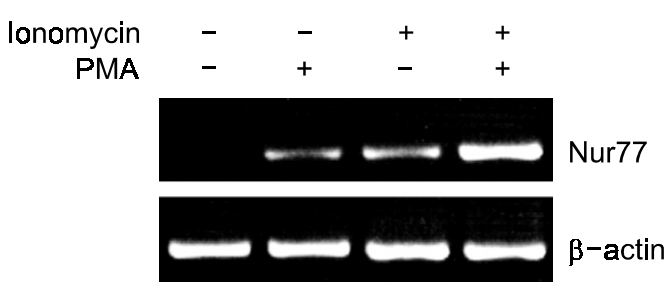

B

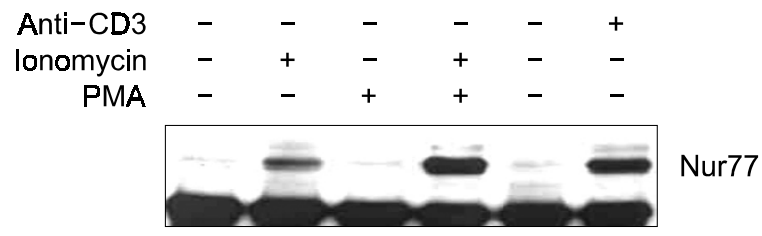

D

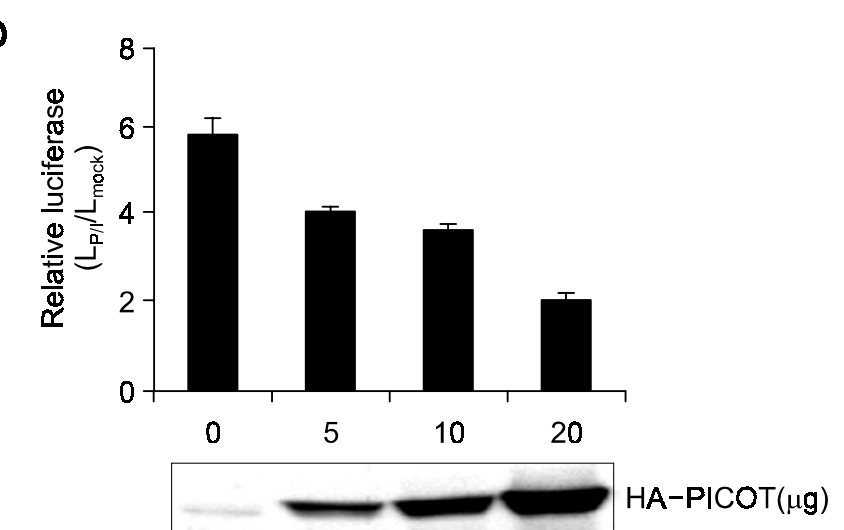

C

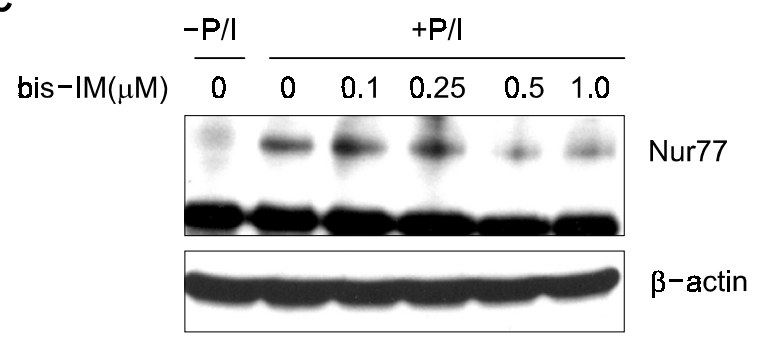

Figure 1. PKC $\theta$ is involved in Nur77 induction. PMA synergizes with ionomycin for the induction of Nur77 at the (A) mRNA and (B) protein level in D011.10 T cells. D011.10 T cells ( $10^{7}$ cells/lane) were treated with ionomycin $(1 \mu \mathrm{M})$, PMA $(40 \mathrm{nM})$, or both or anti-CD3 monoclonal antibody for $3 \mathrm{~h}$. RT-PCR was performed using extracted total RNAs. For immunoprecipitation, cell lysates were incubated with anti-Nur77 antibody for $2 \mathrm{~h}$. Immunoprecipitates were subjected to $8 \%$ SDS-PAGE, transferred to nitrocellulose membrane, then western blotted with anti-Nur77 antibody. (C) A PKC inhibitor, Bisindolylmaleimide I (bis-IM) reduces the induction of Nur77. D011.10 T cells were pretreated with varying concentrations of bis-IM for $30 \mathrm{~min}$, followed by addition of PMA and ionomycin for another $3 \mathrm{~h}$. The samples were processed as in (B). (D) PICOT, an endogenous PKC $\theta$ inhibitory protein also reduces the induction of Nur77. T cells were transfected with pNur77 (-337)-luc reporter gene, pEFPKC $\theta$ (A148/E), and increasing amounts of pSG5-HA-PICOT. PMA and ionomycin were added $16 \mathrm{~h}$ post-transfection. Luciferase activities were normalized with protein concentrations.

determine whether PKC $\theta$ is involved in Nur77 induction, we transiently transfected DO11.10 cells with HA-tagged PICOT, an endogenous PKC $\theta-$ specific inhibitor along with Nur77 promoter-driven luciferase reporter plasmid (Witte et al., 2000). Similar to bis-IM, PICOT also inhibited the activation of the Nur77 reporter gene in a dose-dependent fashion, indicating that PKC $\theta$ serves as an activator for Nur77 induction in T cell (Figure 1D).

\section{Mapping of PKC $\theta-$ responsive element in Nur77 promoter}

Although PMA can induce mRNA of Nur77, its effect was transient (Figure 1A). Previously, the PMA response can be observed using a Nur77-luciferase reporter gene (Youn et al., 1999). To further increase the sensitivity of the Nur77 reporter assay to PKC signaling, we overexpressed a constitutively active form of PKC $\theta$ that harbors a mutation of Ala148 to Glu. It was found that overexpression of PKC $\theta$ (A148/E) is sufficient to activate the Nur77-luciferase reporter to a level well above the background. Using this assay, we investigated the PKC $\theta$-responsive DNA element in Nur77 promoter by transient transfection of D011.10 cells with serial deletion mutants of Nur77 promoter-luciferase reporter plasmids along with the constitutively-active PKC $\theta$ (A148/E) (Figure $2 \mathrm{~A})$. The deletion of the Nur77 promoter to -337 had no effect on PKC $\theta$-mediated reporter activities. Further deletion to -250 results in a less than $50 \%$ decrease in Nur77 promoter activity. There are two calcium-dependent MEF2 responsive elements between -297 and -288 , and -262 and -253 , indicating that MEF2D is, slightly, but not critically, regulated by PKC $\theta$. Importantly, deletion of nucleotides -250 to -216 resulted in a dramatic decrease in Nur77-luciferase reporter gene activity, indicating that $\mathrm{PKC} \theta$ responsive element is localized between -250 and $-226 \mathrm{bp}$. This region contains a putative AP-1 like element (TGCGTCA, -234 and -228) even though it is not a perfect match to AP-1 consensus sequence. To further confirm the role of the newly identified AP-1 like element in PKC $\theta$-mediated Nur77 induction, we generated a mutant reporter plasmid of AP-1 like responsive element by converting TGCGTCA (wild type) to TGCGTTG (mutant) (Figure 2B). Mutation of AP-1 like site results in dramatic decrease of Nur77 
A

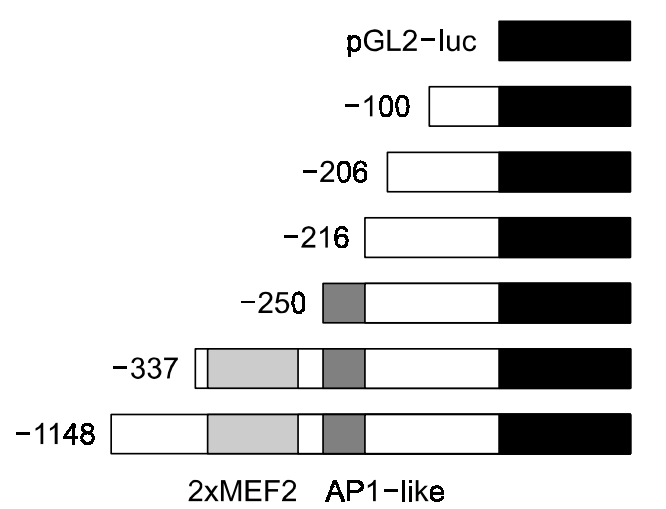

B

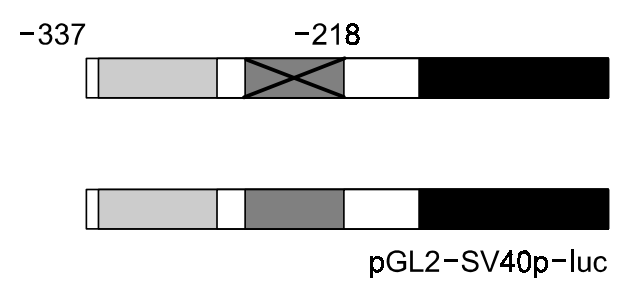

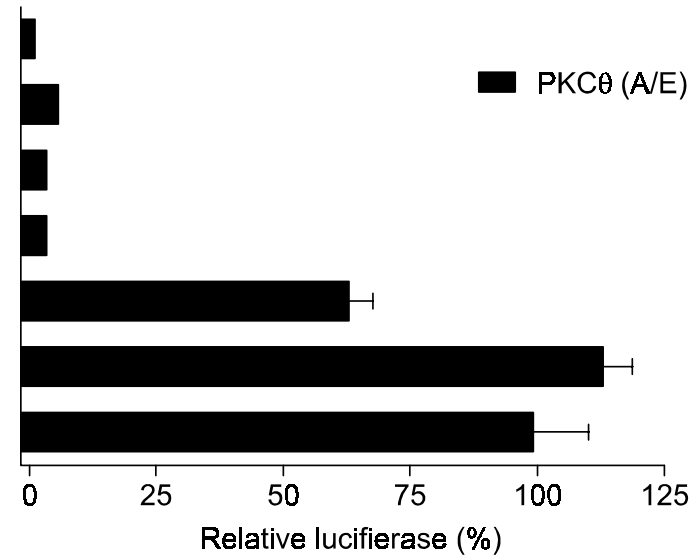

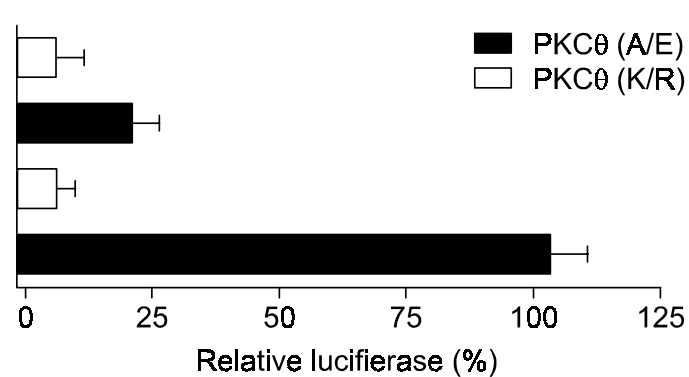

Figure 2. PKC $\theta$ activates the Nur77 promoter through the AP1-like element. (A) Mapping of PKC $\theta$-responsive element on Nur77 promoter. (B) AP1-like element is important for PKC $\theta$-mediated activation of Nur77. D011.10 cells were transfected with constitutively-active PKC $\theta$ along with deletion mutants of Nur77 promoters [pNur77 (-337 to -216/WT)-luc or (pNur77 (-337 to -216/Mut)-luc).

promoter activity, indicating that AP-1 like element is crucial for PKC $\theta$-mediated induction of Nur77.

When we performed gel shift assay with ${ }^{32} \mathrm{P}$ labelled AP-1 like probe derived from the PKC $\theta$ response element in the Nur77 promoter, we detected a single binding protein from nuclear extracts prepared from cells with or without prior treatment with PMA and ionomycin (Figure 3A). To identify the protein that is bound to the AP-1 like element, we performed supershift assay with either anti-c-jun or anti-JunD antibody. Treatment with anti-JunD antibodies leads to the appearance of a super-shifted band (Figure $3 A$ ), indicating that JunD is part of the complex that bound to the AP-1 like element. In contrast, anti-c-Jun antibody did not cause any super-shift of the band. It is worth noting that the protein-DNA complex did not change as a result of stimulation with PMA and ionomycin, consistent with the fact that JunD is constitutively expressed in T cells. Independently, we also determined the binding of JunD to the AP-1 like element using AP-1 like biotinylated oligonucleotide (Figure 3B).
PKC $\theta$ indirectly phosphorylates JunD through the activation of MAP kinases

As PKC $\theta$ is a protein kinase, we tested if $P K C \theta$ can phosphorylate JunD by transient transfection of HAJunD along with PKC $\theta$ (A148/E). Cell lysates were immunoprecipitated with anti-HA antibody and then probed with either anti-HA or anti-phospho-JunD S100) antibody. Coexpression of the constitutively active form of PKC $\theta$ caused a significant level of phosphorylation of JunD (Figure 4A). The lack of a consensus phosphorylation site in JunD for PKC $\theta$ prompted us to test other kinases as well as $\operatorname{PKC} \theta$ in vitro. We incubated recombinant GST-JunD with immunoprecipitates of anti-PKC $\theta$, anti-JNK, or anti-ERK antibody, respectively, from PKC $\theta$ (A148/E)- activated cell lysates. PKC $\theta$ can not directly phosphorylate JunD, but ERK and JNK can both directly phosphorylate JunD (Figure 4B).

\section{Menin represses PKC $\theta /$ p300-mediated activation of JunD in the Nur77 promoter}

That JunD, unlike c-Jun, is not inducible in T cells and its binding to the PKC $\theta$-responsive element in 
A

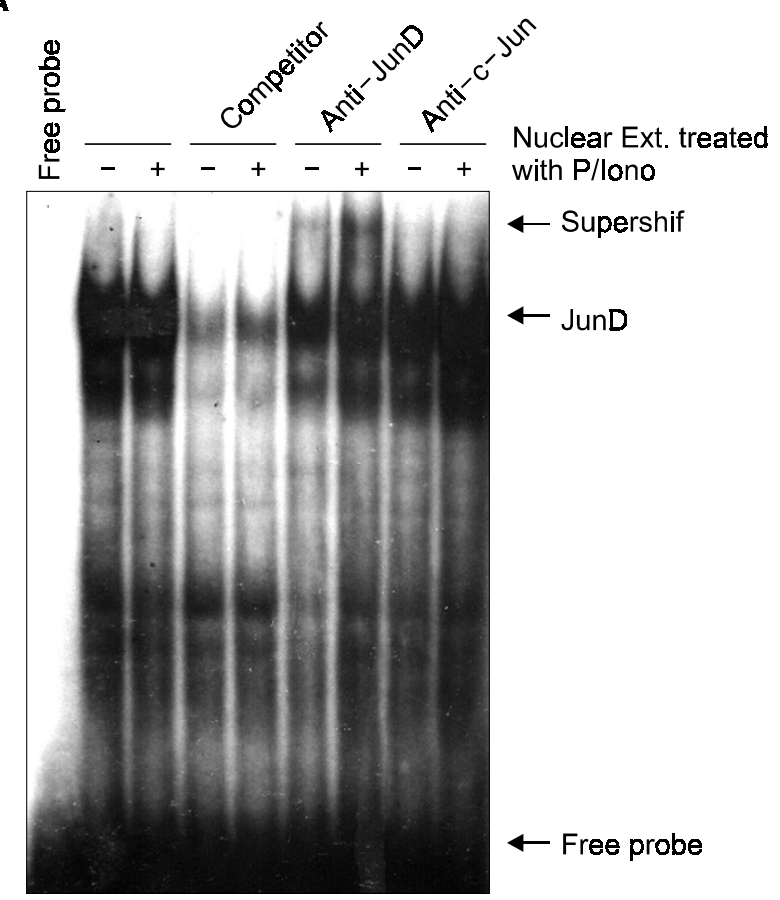

B

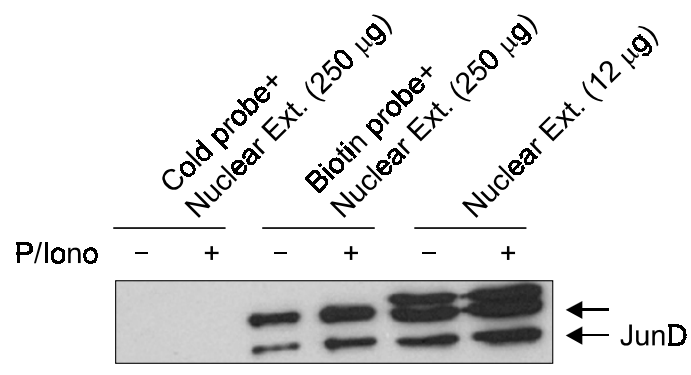

Figure 3. JunD binds to the AP1-like element in Nur77 promoter. (A) Electrophoretic mobility shift assay. Nuclear extracts $(5 \mu \mathrm{g})$ prepared from cells treated with PMA and ionomycin, or none, were incubated with ${ }^{32} \mathrm{P}$-labelled probe. Samples were subjected to $4 \%$ polyacrylamide gel electrophoresis and the binding of JunD was detected by autoradiography. For supershift assay, anti-JunD or anti-c-jun antibody was preincubated with the nuclear extracts prior to addition of ${ }^{32} \mathrm{P}$-labelled probe. (B) Biotin-streptavidin pull-down assay. Nuclear extracts $(250 \mu \mathrm{g})$ from naïve or PMA/ionomycin-treated D011.10 cells were incubated with biotin-labelled probe for $2 \mathrm{~h}$ in the presence of stretavidin-beads, washed with washing buffer. Boiled samples were loaded into $10 \%$ SDS-PAGE, transferred to nitrocellulose membrane, and immunoblotted with anti-JunD antibody.

the Nur77 promoter is not affected by PKC signal is reminiscent of MEF2. As MEF2 undergoes a signaldependent switch from a transcriptional repressor to an activator by dissociation from corepressor complexes and association with coactivators, we speculated that JunD might also regulate Nur77 promoter in a similar manner. In fact, Menin, identified

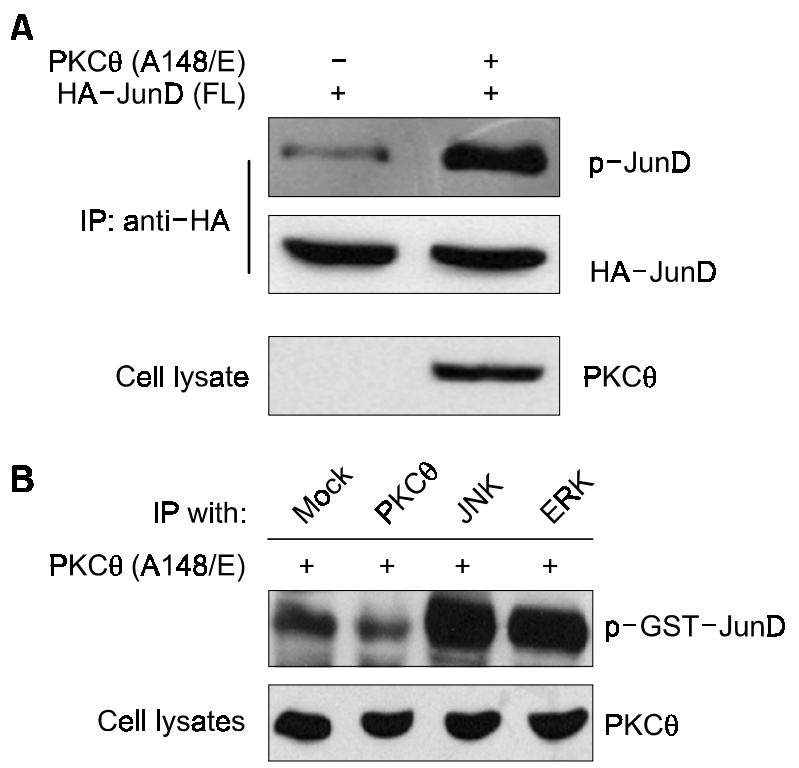

Figure 4. PKC $\theta$ regulates JunD. (A) PKC $\theta$ causes phosphorylation of JunD at serine 100. Cells were transfected with PSG-HA-JunD alone or along with pEF-PKC $\theta$ (A148/E). Immunoprecipitates of HA-JunD was immunoblotted with anti-phospho-JunD (S100) antibody. (B) Phosphorylation of JunD by PKC $\theta$-activated MAP kinases. Cells were transfected with $\mathrm{pEF}-\mathrm{PKC} \theta$ (A148/E) followed by immunoprecipitations with anti-PKC $\theta$, anti-JNK, and anti-Erk antibadies. GST-JunD was incubated with each of immunoprecipitates. Phosphorylation of GST-JunD was determined by immunoblotting with anti-phospho-JunD (S100) antibody.

as a target gene of multiple endocrine neoplasia type I, has been known to bind to JunD and repress its transcriptional activity (Aggarwal et al., 1999). The Menin-mediated repression of JunD can be reversed by trichostatinA (Gobl et al., 1999), suggesting that Menin may be exerting its transcriptional repression effect on JunD by recruiting histone deacetylases. Recently we showed that Menin serves as a JunD repressor through the recruitment of an $\mathrm{mSin} 3 \mathrm{~A}$-histone deacetylase complex (Kim et al., 2003). However, it remains unclear how Menin in T cell is still associated with HDACs to repress JunDdriven Nur77 expression. To address this question, we transiently transfected Jurkat cells with Nur77 promoter-driven reporter gene along with the increasing amount of Menin (Figure 5A). PKC $\theta$ (A148/ E) increases the Nur77 reporter activity, whereas increase of Menin gradually decreases the PKC $\theta$ (A148/E)-mediated Nur77 reporter activity, supporting that Menin represses PKC $\theta$ activation of Nur77 in T cells.

We investigated the interaction of JunD with p300 by transient transfection of HA-tagged JunD (pSGHA-JunD) along with either $\mathrm{N}$-terminal domain of p300 (pcdef3-flag-p300(1-682)) or C-terminal domain of p300 (pcdef3-flag-p300(1737-2414)). Under 
A

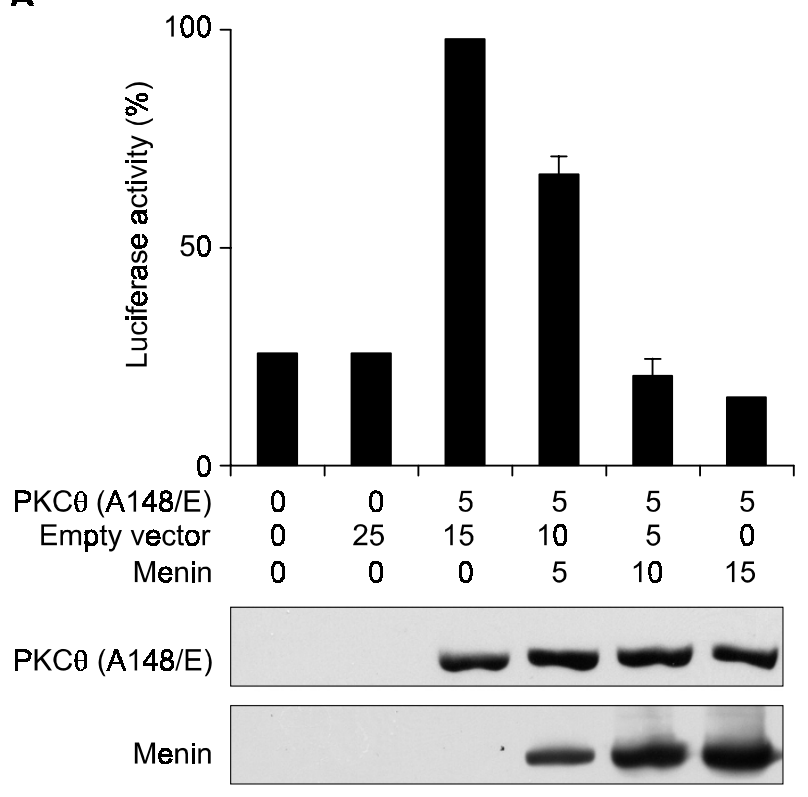

C

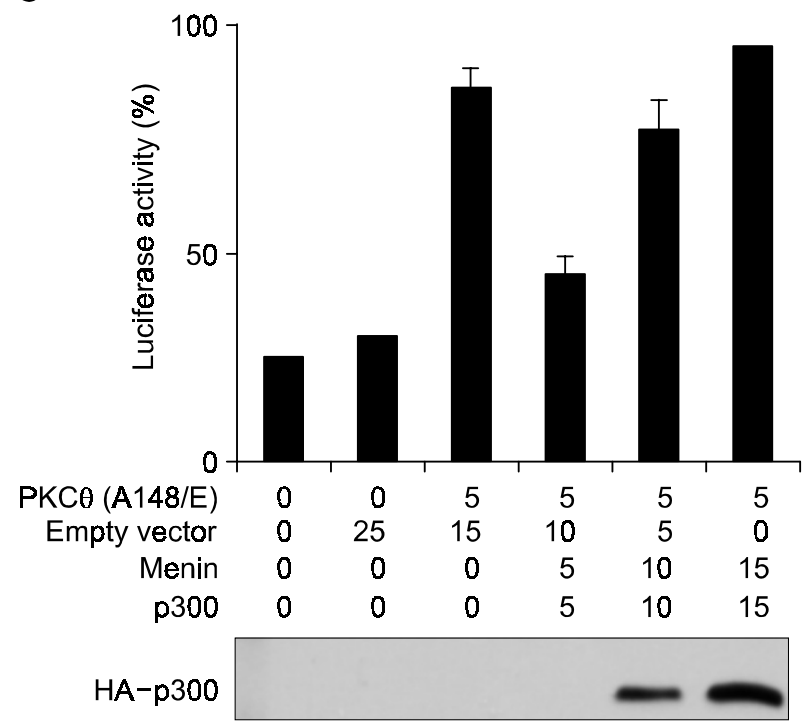

B

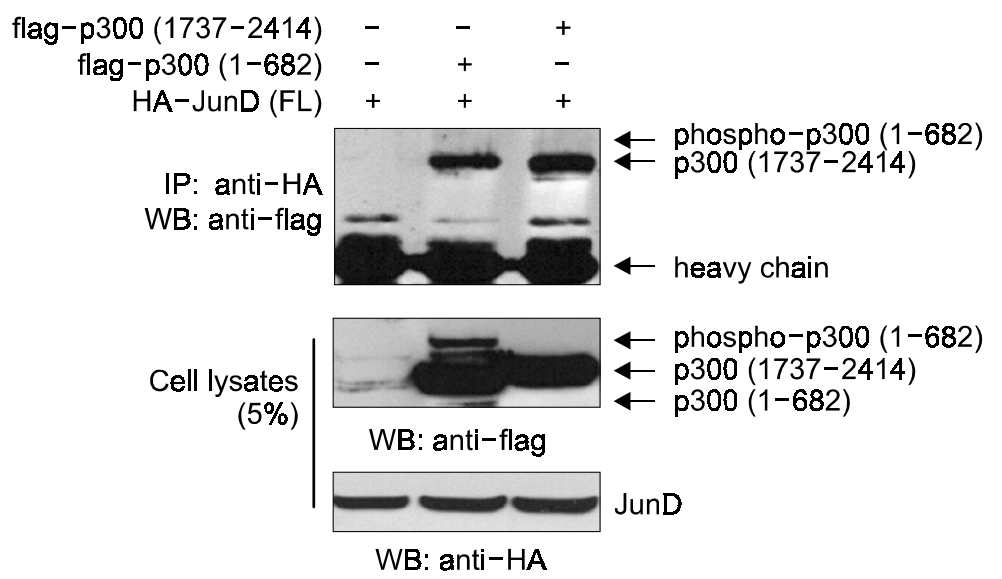

Figure 5. Menin represses PKC $/ \mathrm{p} 300$-mediated activation of JunD in T cell. (A) Menin represses PKC $\theta$-mediated transactivation of JunD under Nur77 promoter-driven luciferase reporter gene. (B) JunD binds to both of $\mathrm{N}$ - and $\mathrm{C}$-terminal domains of $\mathrm{p} 300$. Cells were transfected with HA-JunD along with flag-tagged p300 (1-682) or flag-tagged p300 (1737-2414). Immunoprecipitates with anti-HA antibody were immunoblotted with anti-flag (M2) antibody. (C) p300 restores Menin-repressed JunD transcriptional activity. Jurkat cells were transfected with different combinations of expression vectors as described in panel. Reporter gene activities were measured and normalized with protein concentration in $(A)$ and $(C)$. This represents the average of three different experiments.

serum-enriched conditions, HA-JunD interacts with both of $\mathrm{N}$-terminal and $\mathrm{C}$-terminal of p300 (Figure $5 B)$. Next we examined whether overexpression of p300 overcomes Menin-repressing activity of JunD using reporter gene assay. Transfection of $\mathrm{PKC} \theta$ alone significantly increases Nur77 reporter gene activity, while cotransfection of Menin decreases reporter gene activity. However, increasing amount of p300 restores Menin-repressed JunD transcriptional activity (Figure 5C), implicating that p300 competes against Menin-HDAC complexes for binding to JunD.

\section{Discussion}

Nur77 family of transcription factor has been known to play a pivotal role in TCR-mediated apoptosis in immature $T$ cells. Usually TCR signaling pathway bifurcates into two major signaling pathways in the cytosol, calcium and PKC pathways. Of two signals, calcium signal is sufficient to induce low level of Nur77 expression (Figure 1A). MEF2D has been shown to mediate calcium-dependent induction of Nur77 (Woronicz et al., 1995). MEF2D is constitutively bound to the Nur77 promoter, switching bet- 
ween an "off" state in the absence of an appropriate TCR signal and an "on" state in the presence of TCR signaling. We recently found that Cabin1 represses MEF2D by recruiting mSin3-histone deacetylase (Youn et al., 1999; Youn and Liu, 2000). Repression of MEF2D by Cabin1 is sensitive to calcium signaling. Calcium-activated calmodulin ( $\mathrm{CaM})$ binds to MEF2D and release Cabin1-HDAC complexes from MEF2. In addition to Cabin1, MITR and Class II HDACs (HDAC4/5/7/9) also repress MEF2D transcriptional activity (Miska et al., 1999; Sparrow et al., 1999; Wang et al., 1999; Dressel et al., 2001). Class II HDACs bind to MEF2 through their $\mathrm{N}$-terminal domain and directly inhibit MEF2 transcriptional activity through their C-terminal of intrinsic HDAC catalytic domain. MITR, lacking in HDAC catalytic domain, has been shown to repress MEF2 by recruitment of CtBP through PXDLR motif (Zhang et al., 2001). We provided evidence that all MEF2 repressors are sensitive to calcium signaling by showing that MEF2-binding domain of these repressors share a CaM-binding domain and $\mathrm{CaM}$ releases these repressors from MEF2 similar to Cabin1 (Youn and Liu, 2000; Youn et al., 2000b).

While much is known about calcium signaling during Nur77 expression in T cells, how PKC pathway activates Nur77 transcription remained largely unknown. It has been shown that $\mathrm{PKC} \theta$, a predominant isoform of $P K C$ in $T$ cells, activates $A P-1$ and $N F-\kappa B$ transcription factors in IL-2 production (Baier-Bitterlich et al., 1996; Sun et al., 2000). However, there are neither $N F-\kappa B$ response element nor exact $A P-1$ element, instead, four AP-1-like elements (TGCGTCA; NAP1, -68 to -62 ; NAP2, -39 to -33 ; NAP3, -212 to -206 , NAP4, -232 to -226 ) in the murine Nur77 promoter. In pheochromocytoma-derived cell line PC12, NGF and membrane depolarization activate Nur77 through binding of JunD to two AP-1-like elements (NAP1 and NAP2), both of which are closest to TATA box (Yoon and Lau, 1994). Moreover, the Tax viral transactivator induces Nur77 by activation of JunD through the same NAP1 and NAP2 (Liu et al., 1999). However, PMA-activation of Nur77 in T cells requires a quite different promoter sequence between -378 to -162 , even though the exact PKC-responsive element in this region has not been confirmed yet (Liu et al., 1994; Woronicz et al., 1994). We identified the PKC $\theta$-responsive element for Nur77 induction in $T$ cells as the AP-1-like element (NAP4, -232 to -226 ), which is in close proximity to calcium-dependent MEF2-responsive element (Figure 2). We confirmed that JunD specifically binds to NAP4 and is activated indirectly by PKC through phosphorylation of JunD by MAP kinases (JNK and ERK) (Figure 5). In ovarian cells, calcium-dependent activation of ERK mediates JunD phosphorylation and Nur77 induction by prostaglandin (Stocco et al., 2002). In this case, JunD induces the Nur77 through NAP1 and NAP2 elements. Interestingly, we found that $\mathrm{PKC} \theta$ specifically synergizes with calcium to induce Nur77 expression only through NAP4, but not through other NAPs in Nur77 promoter, probably due to that JunD may cooperate with MEF2D since NAP4 is localized near the MEF2-responsive element. It is known that p300 bridges two discrete transcription factors and augments their transcriptional activities by cooperative recruitment of two transcription factors through $\mathrm{N}$ terminal and C-terminal domain of p300 (Nakashima et al., 1999). In fact, MEF2D binds to both of $\mathrm{N}$ terminal and C-terminal domain of p300 (Youn et al., 1999), and JunD also interacts with both of $\mathrm{N}$ terminal and C-terminal domain of p300 (Figure 5B). Therefore, it is possible that p300 simultaneously interacts with both of MEF2D and JunD and integrates two transcriptional activities for Nur77 induction. It is very interesting that Nur77 induction in $\mathrm{T}$ cell differs from that in other cell types in that $\mathrm{T}$ cell requires MEF2 transcription factor for Nur77 expression, while other cell types just require JunD activity through NAP1 and NAP2 closest to TATA box (Youn and Lau, 1994; Stocco et al., 2002).

JunD differs from other AP-1 family of transcription factors in that JunD is expressed constitutively at high levels and has no transforming activity (Hirai et al., 1989; Ryder et al., 1989; Hartl et al., 1991). More distinctly, Menin, originally identified as a tumor suppressor, is a nuclear protein and specifically binds to JunD, but not other AP-1 family of transcriptional factors (c-Jun, JunB) and represses its transcriptional activity (Aggarwal et al., 1999). The mechanism by which Menin represses JunD is still unclear. Recently, it was suggested that Menin inhibits JunD transcriptional activity by uncoupling of MAP kinase activation from MAP kinase-mediated phosphorylation of JunD (Gallo et al., 2002). Recently, we provided direct evidence that Menin recruits HDACs through association with $\mathrm{mSin} 3 \mathrm{~A}$, a general transcriptional corepressor (Kim et al., 2003). On the contrary, PKC activation triggers phosphorylation of $\mathrm{N}$-terminal domain of JunD. It is well known that $\mathrm{N}$-terminal phosphorylation of c-Jun (S63 and S73) is required for CBP binding (Bannister et al., 1995). Like c-jun, JunD has two conserved serine residues at its $\mathrm{N}$-terminus. Overexpression of constitutivelyactive $\mathrm{PKC} \theta$ triggers phosphorylation of $\mathrm{N}$-terminal serine (100) residue, which probably mediates recruitment of p300 and enhances JunD transcriptional activity. Based on the reporter gene assay, increasing amount of p300 restores Menin-repressed JunD activity. However, we still cannot explain the molecular mechanism by which JunD switches partners 
from Menin-mSin3-HDAC to p300 (or CBP) upon TCR activation. As Menin-binding domain in JunD is different from the p300-binding domain, it is not likely that Menin directly competes p300 for JunD binding. In biochemical binding assay in vitro, we failed to detect competition between Menin and p300 for association with JunD (data not shown). How JunD changes chromatin modifiers upon TCR activation remains to be addressed in the future.

In conclusion, we have identified the major DNA response element to PKC signal as an AP-1 like element in the Nur77 promoter. We found that JunD is the predominant isoform of AP-1 family that is bound to this element. Similar to the calcium-sensitive transcription factor, JunD is capable of silencing the Nur77 promoter by recruiting the MeninmSin3-HDAC complex or activating the promoter by recruiting p300. The simultaneous existence of two HDAC containing complexes on the Nur77 promoter though MEF2 and JunD, respectively, may serve to ensure complete silencing of the Nur77 promoter in the absence of an appropriate TCR signal.

\section{Acknowledgement}

We are grateful to Drs. A. Altman, S. K. Agarwal, C. $X$. Zhang and A. Gobl for DNA constructs. This work was supported by grants from Cancer Research Institute, Seoul National University College of Medicine (CRI-04-6), Seoul National University Hospital (03-2004-010-0), Korean Science \& Engineering Foundation (KOSEF, R01-2002-000-00242-0, H.-D. Y).

\section{References}

Agarwal SK, Guru SC, Heppner C, Erdos MR, Collins RM, Park SY, Saggar S, Chandrasekharappa SC, Collins FS, Spiegel AM, Marx SJ, Burns AL. Menin interacts with the AP1 transcription factor JunD and represses JunD-activated transcription. Cell 1999;96:143-52

Altman A, Isakov N,Baier G. Protein kinase C theta: a new essential superstar on the T-cell stage. Immunology Today 2000; 21:567-73

Baier G, Telford D, Giampa L, Coggeshall M, Baier-Bitterlich G, Isakov N, Altman A. Molecular cloning and characterization of PKC theta, a novel member of the protein kinase $C$ (PKC) gene family expressed predominantly in hematopoietic cells. J Biol Chem 1993;268:4997-5004

Baier-Bitterlich G, Uberall F, Bauer B, Fresser F, Wachter $\mathrm{H}$, Grunicke H, Utermann G, Altman A, Baier G. Protein kinase C-theta isoenzyme selective stimulation of the transcription factor complex AP-1 in T lymphocytes. Mol Cell Biol 1996; 16:1842-50

Bannister AJ, Oehler T, Wilhelm D, Angel P, Kouzarides T. Stimulation of c-Jun activity by CBP: C-Jun residues ser63/ 73 are required for $\mathrm{CBP}$ induced stimulation in vivo and $\mathrm{CBP}$ binding in vitro. Oncogene 1995;11:2509-14

Blaeser F, Ho N, Prywes R, Chatila TA. Ca2+-dependent gene expression mediated by MEF2 transcription factors. J Biol Chem 2000;275:197-209

Chandrasekharappa SC, Guru SC, Manickam P, Olufemi SE, Collins FS, Emmert-Buck MR, Debelenko LV, Zhuang Z, Lubensky IA, Liotta LA, Crabtree JS, Wang Y, Roe BA, Weisemann J, Boguski MS, Agarwal SK, Kester MB, Kim YS, Heppner C, Dong Q, Spiegel AM, Burns AL, Marx SJ. Positional cloning of the gene for multiple endocrine neoplasia-type 1.Science 1997;276:404-7

Dequiedt F, Kasler H, Fischle W, Kiermer V, Weinstein M, Herndier BG, Verdin E. HDAC7, a thymus-specific class II histone deacetylase, regulates Nur77 transcription and TCRmediated apoptosis. Immunity 2003;18:687-98

Dressel U, Bailey PJ, Wang SC, Downes M, Evans RM Muscat GE. A dynamic role for HDAC7 in MEF2-mediated muscle differentiation. J Biol Chem 2001;276:17007-13

Gallo A, Cuozzo C, Esposito I, Maggiolini M, Bonofiglio D, Vivacqua A, Garramone M, Weiss C, Bohmann D, Musti AM. Menin uncouples Elk-1, JunD and C-Jun phosphorylation from MAP kinase activation. Oncogene 2002;21:6434-45

Gobl AE, Berg M, Lopez-Egido JR, Oberg K, Skogseid B, Westin G. Menin represses JunD-activated transcription by a histone deacetylase-dependent mechanism. Biochim Biophys Acta 1999;1447: 51-6

Hartl M, Hutchins JT, Vogt PK. The chicken junD gene and its product. Oncogene 1991;6:1622-31

Heppner C, Bilimoria KY, Agarwal SK, Kester M, Whitty LJ, Guru SC, Chandrasekharappa SC, Collins FS, Spiegel AM, Marx SJ, Burns AL. The tumor suppressor protein menin interacts with NF-kappaB proteins and inhibits NF-kappaBmediated transactivation. Oncogene 2001;20:4917-25

Hirai SI, Ryseck RP, Mechta F, Bravo R, Yaniv M. Characterization of junD: a new member of the jun proto-oncogene family. EMBO J 1989;8:1433-9

Kaji H, Canaff L, Lebrun JJ, Goltzman D, Hendy GN. Inactivation of menin, a Smad3-interacting protein, blocks transforming growth factor type beta signaling. Proc Natl Acad Sci USA 2001;98:3837-42

Kim H, Lee J-E, Cho E-J, Liu JO, Youn H-D. Menin, a tumor suppressor, represses JunD-mediated transcriptional activity by association with an mSin3A-histone deacetylase complex. Cancer Res 2003;63:6135-9

Lai MM, Burnett PE, Wolosker H, Blackshaw S, Snyder SH. Cain, a novel physiologic protein inhibitor of calcineurin. J Biol Chem 1998;273:18325-31

Lemmens IH, Forsberg L, Pannett AA, Meyen E, Piehl F, Turner JJ, Van de Ven WJ, Thakker RV, Larsson C, Kas K. Menin interacts directly with the homeobox-containing protein Pem. Biochem Biophys Res Commun 2001;286: 426-31

Li H, Kolluri SK, Gu J, Dawson MI, Cao X, Hobbs PD, Lin B, Chen GQ, Lu JS, Lin F, Xie Z, Fontana JA, Reed JC, Zhang $\mathrm{XK}$. Cytochrome $\mathrm{c}$ release and apoptosis induced by mito- 
chondrial targeting of nuclear orphan receptor TR3. Science 2000;289:1159-64

Liu X, Chen X, Zachar V, Chang C, Ebbesen P. Transcriptional activation of human TR3/nur77 gene expression by human T-lymphotrophic virus type I Tax protein through two AP-1-like elements. J Gen Virol 1999;80:3073-81

Liu Z-G, Smith SW, McLaughlin KA, Schwartz LM, Osborne $B$. Apoptotic signals delivered through the T-cell receptor of a T-cell hybrid require the immediate-early gene nur77. Nature 1994;367:281-4

Lu S, Wu Q, Ye X-F, Cai JH, Huang ZW, Su WJ. Induction of apoptosis by TPA and VP-16 is through translocation of TR3. World J Gastroenterol 2002;8:446-50

McKinsey TA, Zhang CL, Lu J, Olson EN. Signal-dependent nuclear export of a histone deacetylase regulates muscle differentiation. Nature 2000;408:106-11

McKinsey TA, Zhang CL, Olson, EN. MEF2: a calcium-dependent regulator of cell division, differentiation and death. Trends Biochem Sci 2002;27:40-7

Miska EA, Karlsson C, Langley E, Nielsen SJ, Pines J, Kouzarides T. HDAC4 deacetylase associates with and represses the MEF2 transcription factor. EMBO J 1999;18: 5099-107

Nakashima K, Yanagisawa M, Arakawa H, Kimura N, Hisatsune T, Kawabata M, Miyazono K, Taga T. Synergistic signaling in fetal brain by STAT3-Smad1 complex bridged by p300. Science 1999;284:479-82

Osada SI, Mizuno K, Saido TC, Suzuki K, Kuroki T, Ohno S. A new member of the protein kinase $C$ family, nPKC theta, predominantly expressed in skeletal muscle. Mol Cell Biol 1992:12:3930-8

Ryder K, Lanahan A, Perez-Albuerne E, Nathans D. Jun-D: a third member of the jun gene family. Proc Natl Acad Sci USA 1989;86:1500-3

Sebzda E, Mariathasan S, Ohteki T, Jones R, Bachmann MF, Ohashi PS. Selection of the T cell repertoire. Annu Rev Immunol 1999;17:829-74

Seo HR, Kwan YW, Cho CK, Bae S, Lee SJ, Soh JW, Chung HY, Lee YS. PKCa induces differentiation through ERK1/2 phosphorylation in mouse keratinocytes. Exp Mol Med 2004;36:292-9

Sparrow DB, Miska EA,, Langley E, Reynaud-Deonauth S, Kotecha S, Towers N, Spohr G, Kouzarides T, Mohun TJ. MEF-2 function is modified by a novel co-repressor, MITR. EMBO J 1999;18:5085-98

Stocco CO, Lau LF, Gibori GA calcium/calmodulin-dependent activation of ERK1/2 mediates junD phosphorylation and induction of nur 77 and $20 \alpha$-hsd genes by prostaglandin F2 $\alpha$ in ovarian cells. J Biol Chem 2002;277:3293-302

Sun L, Youn H-D, Loh C, Stolow M, He W, Liu JO. Cabin 1, a negative regulator for calcineurin signaling in $\mathrm{T}$ lymphocytes. Immunity 1998;8:703-11
Sun Z, Arendt CW, Ellmeier W, Schaeffer EM, Sunshine MJ, Gandhi L, Annes J, Petrzilka D, Kupfer A., Schwartzberg PL, Littman DR. PKC-theta is required for TCR-induced NFkappaB activation in mature but not immature $\mathrm{T}$ lymphocytes. Nature 2000;404:402-7

Uemura $\mathrm{H}$, Chang $\mathrm{C}$. Antisense TR3 orphan nuclear receptor can increase prostate cancer cell viability with etoposide treatment. Endocrinology 1998;129:2329-34

Wang $\mathrm{AH}$, Bertos NR, Vezmar M, Pelletier N, Crosato M, Heng $\mathrm{HH}$, Th'ng J, Han J, Yang XJ. HDAC4, a human histone deacetylase related to yeast HDA1, is a transcriptional corepressor. Mol Cell Biol 1999;19:7816-27

Weih F, Ryseck RF, Chen L, Bravo R. Apoptosis of nur77/ N10-transgenic thymocytes involves the Fas/Fas ligand pathway. Proc Natl Acad Sci USA 1996;93:5533-8

Winoto A, Littman DR. Nuclear hormone receptors in T lymphocytes. Cell 2002;109:57-66

Witte S, Villalba M, Liu Y, Isakov N, Altman A. Inhibition of the c-Jun N-terminal kinase/AP-1 and NF-kB pathway by PICOT, a novel protein kinase C-interacting protein with a thioredoxin homology domain. J Biol Chem 2000;275:1902-9

Woronicz JD, Calnan B, Ngo V, Winoto A. Requirement for the orphan steroid receptor Nur77 in apoptosis of T-cell hybridomas. Nature 1994;367:277-81

Woronicz JD, Lina A, Calnan BJ, Szychowski S, Cheng L, Winoto A. Regulation of the Nur77 orphan steroid receptor in activation-induced apoptosis. Mol Cell Biol 1995;15:6364-76

Yoon JK, Lau LF. Involvement of JunD in transcriptional activation of the orphan receptor gene nur77 by nerve growth factor and membrane depolarization in PC12 cells. Mol Cell Biol 1994;14:7731-43

Youn H-D, Sun L, Prywes R, Liu JO. Apoptosis of T cells mediated by $\mathrm{Ca} 2+$-induced release of the transcription factor MEF2. Science 1999;286:790-3

Youn H-D, Chatila TA, Liu JO. Integration of calcineurin and MEF2 signals by the coactivator p300 during T-cell apoptosis. EMBO J 2000a;19:4323-31

Youn H-D, Grozinger CM, Liu JO. Calcium regulates transcriptional repression of myocyte enhancer factor 2 by histone deacetylase 4. J Biol Chem 2000b; 275:22563-7

Youn H-D, Liu JO. Cabin1 represses MEF2-dependent Nur77 expression and T cell apoptosis by controlling association of histone deacetylases and acetylases with MEF2. Immunity 2000;13:85-94

Zhang CL, McKinsey TA, Lu JR, Olson EN. Association of $\mathrm{COOH}$-terminal-binding protein (CtBP) and MEF2-interacting transcription repressor (MITR) contributes to transcriptional repression of the MEF2 transcription factor. J Biol Chem 2001:276:35-9 